\title{
Low-velocity impact responses of Napier fibre/polyester composites
}

\author{
I. Fahmi ${ }^{1}$, M.S. Abdul Majid ${ }^{1 *}$, M. Afendi ${ }^{1}$, Helmi E.A. ${ }^{2}$, M. Haameem J.A. ${ }^{1}$ \\ ${ }^{1}$ School of Mechatronic Engineering, Universiti Malaysia Perlis, Arau, Malaysia \\ ${ }^{2}$ Advanced Material Research Centre (AMREC), SIRIM Berhad, Kulim, Malaysia. \\ Email: shukry@unimap.edu.my
}

\begin{abstract}
The low-velocity impact response of Napier grass fibre/polyester composites was investigated. Napier grass fibre was used as the reinforcing material in polyester composite laminates. Napier/polyester composites specimens of 10\%, 15\%, 20\%, $25 \%$ and $30 \%$ fibre volume fraction were produced using a compression moulding machine. The specimens of the mentioned fractions were impacted with a $5 \mathrm{~J}$ energy level using an instrumented drop weight impact tester (IMATEK IM10). The fracture damage of the impacted specimen was analysed using a field-emission scanning electron microscope (FESEM). The experimental result shows the relationship between the volume fraction percentage of Napier fibres and the impact force, energy absorbed and stiffness of the composites. Pure polyester specimens displayed brittle behaviour with a lower peak force, lower energy absorption and less time to failure compared to Napier reinforced composites. The impacted Napier/polyester composites with fibre loading of $30 \%$ show higher absorbed energy, peak force and longer time to failure. Furthermore, the experiments on each fibre volume fraction revealed increasing load-bearing capability and energy absorption with an increase in the volume fraction of Napier fibre. The FESEM observation exhibits various failure mechanisms such as fibre breakage, fibre pull-out, matrix cracking and fibre splitting.
\end{abstract}

Keywords: Natural fibre; Instrumented drop weight impact test; Napier fibre; Impact; Natural fibre composite.

\section{INTRODUCTION}

Natural plant fibres are credible monetarily and naturally helpful distinct options for the fortification by fibres in polymeric composites [1-4]. Due to their low density, light weight, and economical material cost, cellulose fibre strengthened composites have an incredible potential for utilisation in designing applications [5, 6]. A developing ecological mindfulness around the world has raised interest in innovative work on ecologically friendly and manageable materials [7-11]. Characteristic plant-based fibres are utilised as reinforcement for composite materials and provide different advantages contrasted with synthetic fibre. Vital aspects of the behaviour of natural plant fibre reinforced polymeric composites are their reaction to an effective load and the limited ability of the composites to withstand it amid their serviceability. The effect of knocks or crashes and falling weights can cause damage to the composite [12]. Significant findings have recommended that characteristic natural fibre composites are exceptionally responsive to impact loading [13-15]. Natural fibre composite has a low impact strength when contrasted with glass fibre strengthened thermoplastic and thermostat composites $[16,17]$. In the more extensive setting, evaluating the impact resistance of a composite 
material has been a challenge, since the breakage shows itself in various structures, for example, delamination at the interface, fibre breakage, matrix splitting and fibre pull-out [18-20]. Because of their involution, a considerable number of their attributes remain unexplained [21]. There has been a lot of experimental and analytical research on lowvelocity impact testing of fibre reinforced composites $[17,22]$. The sensitivity of lowvelocity impact damage to glass fibre strengthened polymeric composite materials has been widely recorded $[19,23]$. There are numerous investigations of the conduct of carbon fibre reinforced epoxy composites under impact loading [24, 25]. However, there is very little reported work on the impact response of natural fibre reinforced composites. This paper investigates the impact responses of Napier fibre reinforced polyester composites with various fibre volume fractions. In this experiment, the drop weight impact test is utilised to determine the force-deformation and force-time behaviour for evaluating the impact performance in terms of assessing the effect of impact on the condition of the load-bearing capabilities, absorbed energy and failure mode. The failure mechanisms of the fractured specimens were evaluated by field emission scanning electron microscopy (FESEM).

\section{Experimental procedure}

\section{Extraction of Napier fibre}

The Napier grass stems were acquired from Bukit Kayu Hitam, Kedah. The water retting process was used to extract the fibre strand from the Napier grass stem. Retting is a microbial methodology that breaks the substance bonds that hold the stem together and permits partition of the fibre strand from the stem. Initially, the root portion of the Napier grass was removed, since only the stem part of Napier grass is needed. Next, the stem was crushed with a mallet and chopped between the stem internodes in order to enable water to diffuse into the inner wall of the grass. The stems were immersed in water for three or four weeks, as shown in Figure 1 (a) and 1 (b). The fibre was extracted manually and dried under the sun for a few days to ensure maximum removal of moisture, as shown in Figure 1 (c).

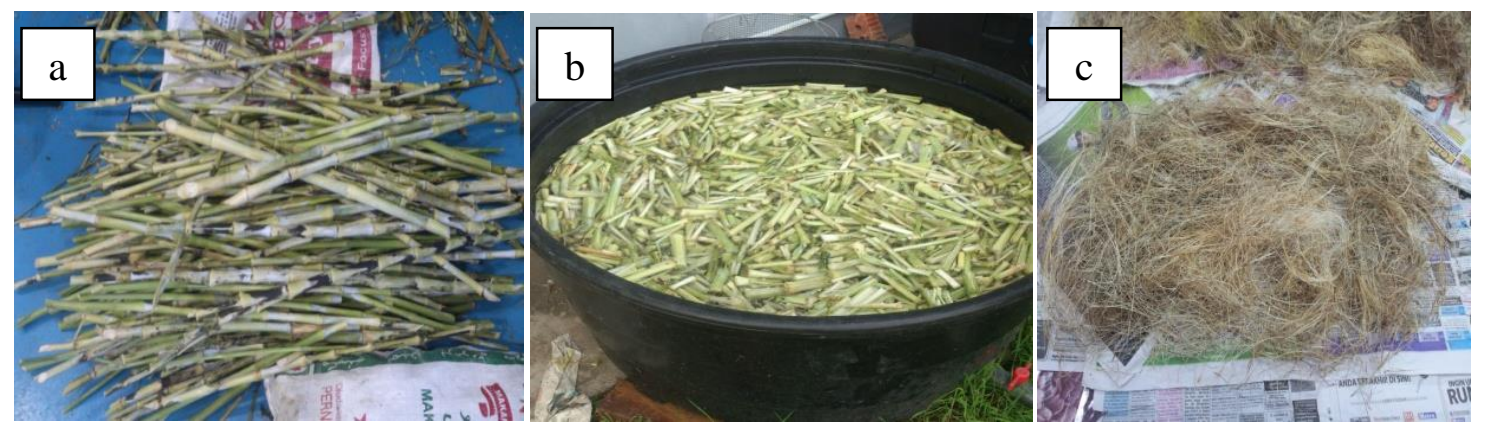

Figure 1. (a) Napier stem; (b) Soaked Napier stem; and (c) Napier fibre strand

\section{Napier/polyester composites preparation}

Figure 2 (a) shows the compression moulding method used in the preparation of Napier grass reinforced composite laminate plate. Firstly the dried extracted fibres were randomly oriented into a mould with a dimension of $300 \times 300 \times 5 \mathrm{~mm}$, creating a ply with $10 \%, 15 \%$, $20 \%, 25 \%$ and $30 \%$ fibre loading. The fibre loading was calculated in accordance with ASTM D3171. The mould was coated with a release agent for ease of removal of the composite plate. Then, a ply of Napier grass fibre was placed in the mould hydraulic 
machine. A measured quantity of polyester and hardener, methyl ethyl ketone (MEKP), was mixed and placed in a mould. The formulated ratio of 100:3 was used for the mixing weight of the polyester and hardener (MEKP). Lastly, the mould was pressed with 5 tonnes for 40 minutes at $50^{\circ} \mathrm{C}$ to cure the composite. The cured laminate was removed from the glass mould, and post-cured at room temperature for 24 hours. The same procedure was repeated with different fibre volume fraction samples as shown in Figure 2 (c).

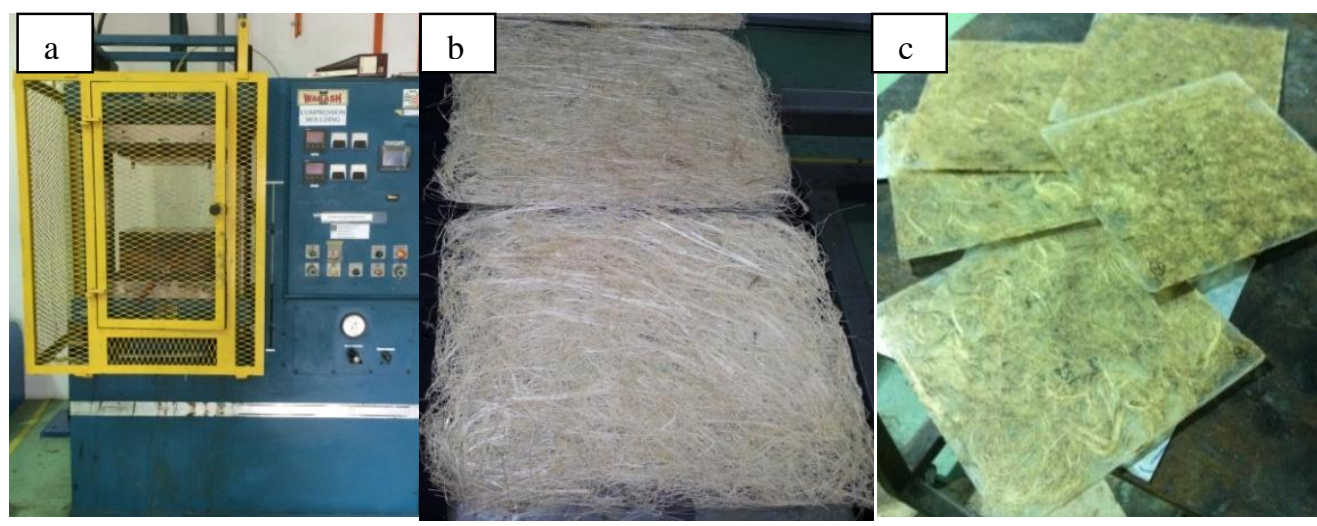

Figure 2. (a) Compression moulding machine; (b) ply of Napier grass fibre; (c) Napier grass fibre composite laminate
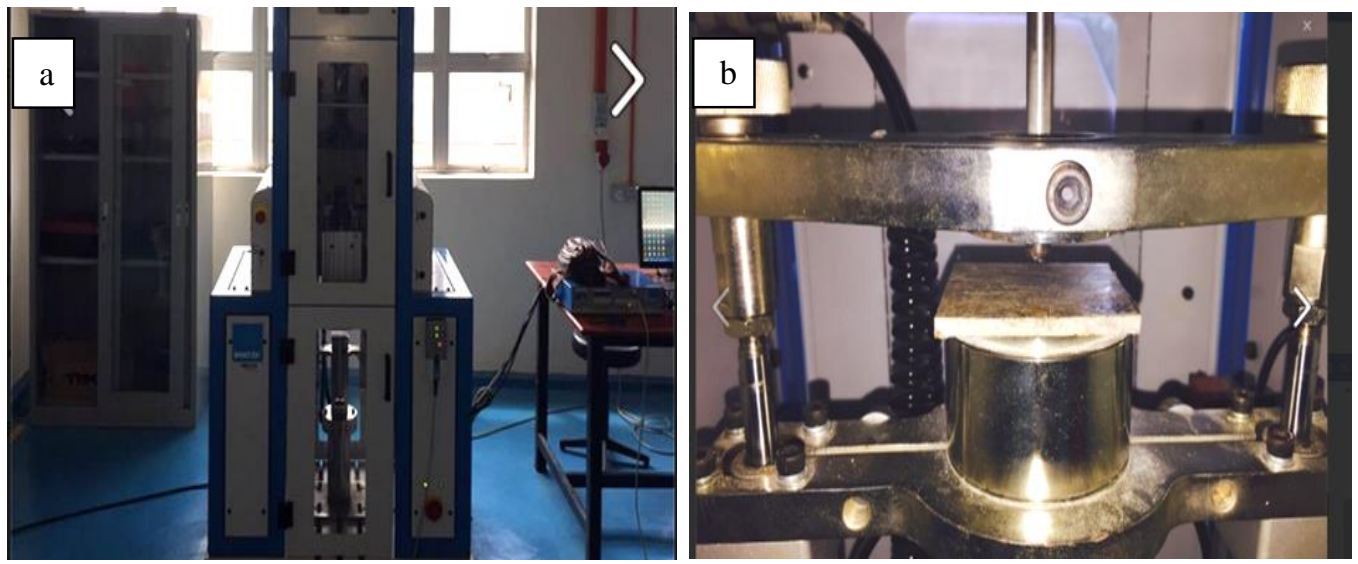

Figure 3. Impact test: (a) Low-velocity impact machine; (b) Impact testing

\section{Drop weight impact test}

A low velocity instrumented drop impact test model IMATEK IM10 was used to conduct the impact test. A $12.7 \mathrm{~mm}$ hemispherical striker was installed in the impactor at a height of $53 \mathrm{~mm}$ and the total mass impactor of $9.6819 \mathrm{~kg}$ was used as shown in Figure 3(b). The total mass in compounding with a freeing height of $53 \mathrm{~mm}$ offered incident energy of $5 \mathrm{~J}$ at a striking velocity of $1.02 \mathrm{~m} / \mathrm{s}$. A square specimen was cut to $80 \times 80 \times 5 \mathrm{~mm}$ from the Napier grass reinforced composite laminate by using a diamond cutter. The specimens were rigidly secured at all borders using annular clamps with inner and outer diameters of 50 and $75 \mathrm{~mm}$. The samples were then impacted, creating damage rising to penetration. The tests were conducted at room temperature for five different fibre loadings; $10 \%, 15 \%$, 
20\%, 25\% and 30\%. Five samples were tested for each test, as stated in ASTM D7136 standard.

\section{Surface morphology study using FESEM}

The fractured surface morphologies of the Napier fibre reinforced composites were examined using a field-emission scanning electron microscope ((FESEM NOVA NANOSEM450). All the cracked segments of the examples were cut; also, platinum was consistently covered over the surfaces before examining. The scanned pictures were acquired with accelerating voltages of $3-5 \mathrm{kV}$, under magnifications of $110 \times$ up to $2000 \times$.

\section{RESULTS AND DISCUSSION}

\section{Impact response of Napier grass fibre reinforced composite}

Five specimens were tested for each fibre volume fraction. Table 1 shows the mean value of the impact test results for the different volume fractions of $10 \%, 15 \%, 20 \%, 25 \%$, and $30 \%$. Throughout, the impact test results of pure polyester are included for comparison. As anticipated, Napier/polyester composites clearly increase both the peak force and total energy absorbed compared to pure polyester.

Table 1. Drop weight impact test results for different volume fractions.

\begin{tabular}{ccc}
\hline Test specimen and fibre volume & Peak force $(\mathrm{kN})$ & Peak energy $(\mathrm{J})$ \\
\hline $0 \%$ (Pure polyester) & 0.54 & 0.26 \\
$10 \%$ & 0.76 & 0.46 \\
$15 \%$ & 0.77 & 0.65 \\
$20 \%$ & 0.91 & 0.89 \\
$25 \%$ & 1.01 & 0.92 \\
$30 \%$ & 1.08 & 1.11 \\
\hline
\end{tabular}

Figure 4 shows the force versus time curve from the drop impact testing. The result indicates that the striker was in longer contact with the composite specimen compared to pure polyester. During the test, the force-time curve yielded almost linear behaviour up to the onset of the damage point. The peak force value for the 10-30\% volume fraction of Napier reinforced specimens and pure polyester was recorded at 0.54 , $0.76,0.77,0.91,1.01$ and $1.08 \mathrm{kN}$ respectively. This indicates that the peak impact force increased with the increase in the volume fraction of the fibre. The Napier reinforced specimens showed superior load-bearing capacity and absorbed more energy during the early stages of the force-time curve before reaching their peak value. This is due to the effect of the Napier fibre reinforcement. As the damage continues to increase and reaches a maximum at the peak force, the Napier reinforced specimen absorbs energy before the specimen is fully penetrated. This stage is visible through visual damage to the specimens. When the visual damage appears, the specimens promptly dissipate their load-bearing capability. The pure polyester specimen, on the other hand, exhibits a small sign of phase generation due to the fact that it contains no fibre reinforcement. The time that expires for the pure polyester to reach perforation is less than for the Napier reinforced samples. Meanwhile, the impact event for the $25 \%$ and $30 \%$ volume fractions of fibre experiences a longer impact time compared to the $10 \%, 15 \%$ and $20 \%$ volume fractions. The peak force in the force-time curve of impact events for the $25 \%$ and $30 \%$ Napier fibre loading demonstrates the higher contact force that the Napier laminate can withstand while being 
subjected to impact loading compared to other specimens. This clearly shows that the reinforced Napier fibre specimen has improved impact properties. A comparable reinforcement effect in other polymer composites is portrayed elsewhere [26, 27]. The drop weight impact test involves small time-scales, as shown in Figure 4. The starting and propagation damage of the pure polyester specimens until perforation was observed at 1-3 ms. The times taken for the impact tests for the $25 \%$ and $30 \%$ composites were approximately 4-9 ms. This signifies that the time difference of the peak force of impact loading is totally affected by the stiffness of the composite. The contact time for impact occurrence increases with the increase in fibre loading in the composite, which continuously stiffens the composite.

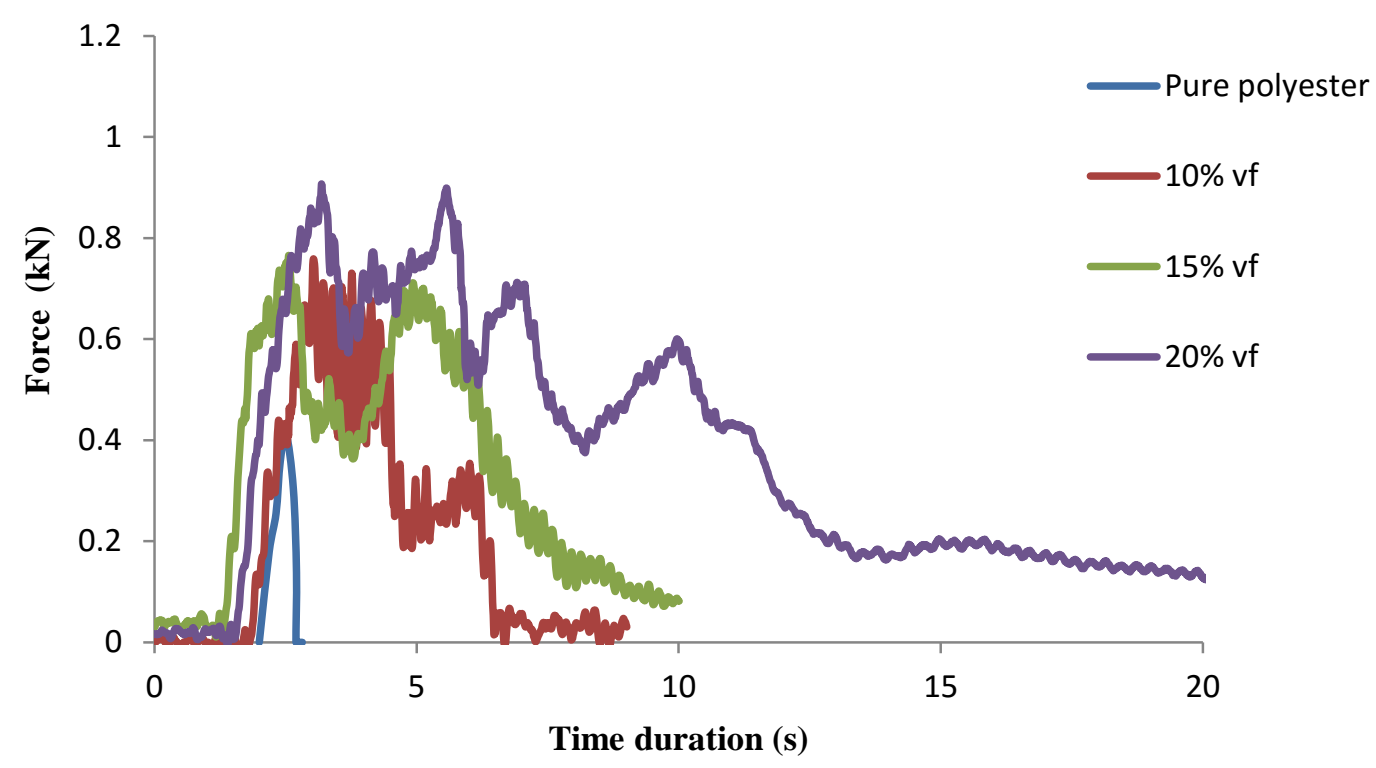

Figure 4. The force-time curve of Napier grass fibre reinforced composites

The failure point of the Napier reinforced composite in the force-time curve in Figure 4 is exemplified in Figure 5 [28]. The force-time effect of the 25\% Napier total fibre fraction specimen is selected as the curve represented for this illustration. Figure 5 presents the four stages of damage progression observed, where no damage appears at stage 1 . When the force increases to stage 2, matrix cracking arises. Moreover, with a further increment of force up to stage 3, the size and cracking of the matrix grow, leading to interfacial debonding [26]. At stage 4, delamination develops due to the interfacial debonding, then there is breakage of the fibre and, lastly, penetration of the impacted sample.

Figure 6 shows the force versus displacement behaviour for pure polyester and Napier reinforced specimens impacted with $5 \mathrm{~J}$ energy levels respectively. The feature of the beginning of the increase in the force-displacement curve interacts with the loadbearing capabilities of the composite. Appearing at a force level of $0.1 \mathrm{kN}$ and displacement of $0.8 \mathrm{~mm}$, the force-displacement curve indicates an alteration in stiffness for pure polyester, signifying structural degradation. For $10-20 \%$ fibre loading of the Napier reinforced samples, the change in stiffness shows that little structural degradation took place at a high force level compared to the pure polyester. In the case of the $25 \%$ and $30 \%$ fibre loading of the Napier reinforced specimens, a change in stiffness (at a force level of 0.6 and $0.7 \mathrm{kN}$ and deformation of 2.0 and $2.75 \mathrm{~mm}$ ) suggested structural 
degradation. The highest value of impact forces failure of the composites increased beginning from the $20-30 \%$ fibre loading specimens.

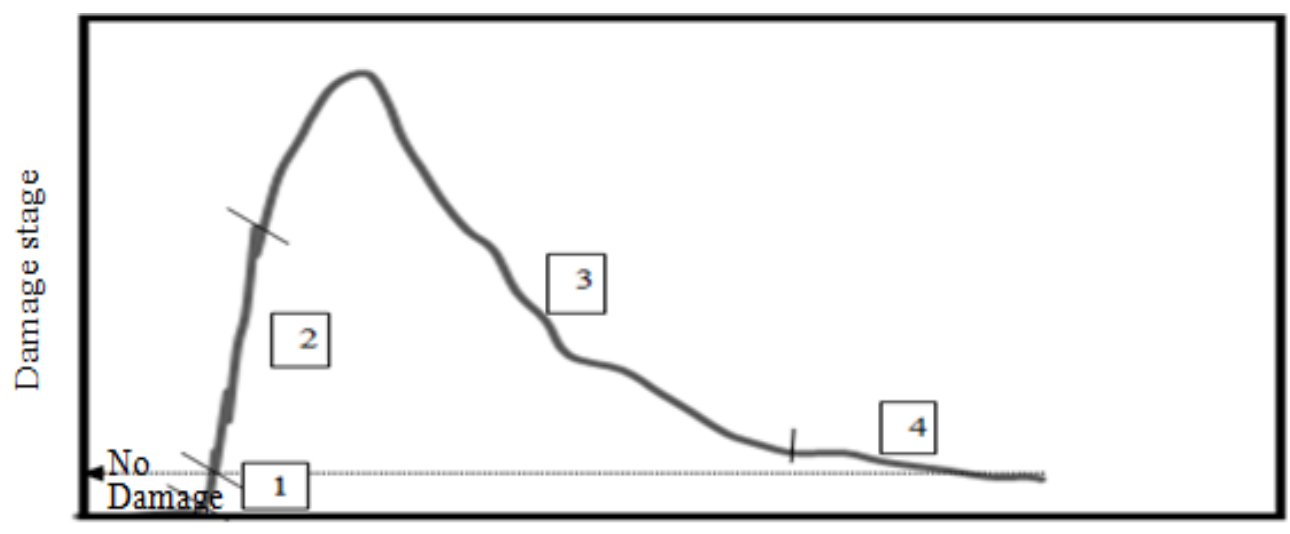

Figure 5. Failure stages of specimen after being subjected to drop impact test

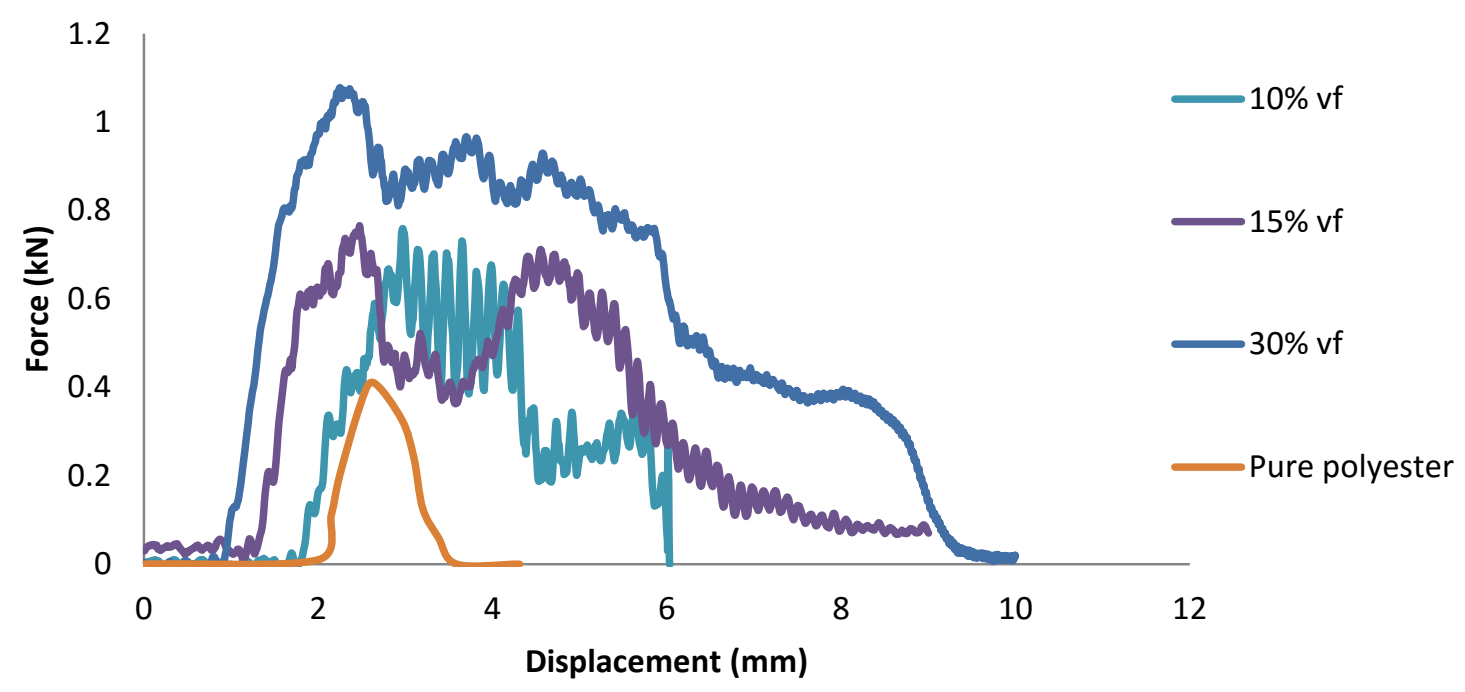

Figure 6. Force-displacement curves of Napier grass fibre reinforced composites.

\section{Energy absorption}

Figure 7 shows the difference in energy absorption during the impact test. The total energy absorption is increased in the Napier reinforced specimens compared to pure polyester. Even though the 10-20\% fibre loading Napier reinforced specimens show much less energy absorption compared with the 25-30\% fibre loading Napier reinforced specimens, this shows the effect of the reinforcement on the pure polyester. The energy applied during an impact test is $5 \mathrm{~J}$ and the $30 \%$ Napier fibre loading specimen absorbs a total energy of $4.8 \mathrm{~J}$, which is almost the same as the applied energy of impact. The energy absorption of pure polyester and 10-30\% Napier fibre loading was recorded as $0.84,1.56$, $2.64,2.93,3.6$ and $4.8 \mathrm{~J}$. The trend of energy absorption indicates that as the fibre loading increases up to its threshold value, the energy absorbed also increases [13]. The impact efficiency of the tested specimens can also be characterised by means of determining the increased loss of kinetic energy of the impact mass during the impact test. By means of calculating the striking speed and residual speed, the absorption with the aid of the impacted specimens can also be analysed by utilising the following formulation: 


$$
E=\frac{1}{2} m\left(v_{i}^{2}-v_{r}^{2}\right)
$$

where $\mathrm{E}$ is the energy dissipated by the target during impact, $\mathrm{m}$ the mass of the impactor, $v i$ the incident velocity and $v r$ the residual velocity after rebound or perforation. $v i$ and $v r$ can also be considered as the initial and final velocity respectively. If the final velocity is less than the initial, then acceleration will be negative and can be termed as deceleration.

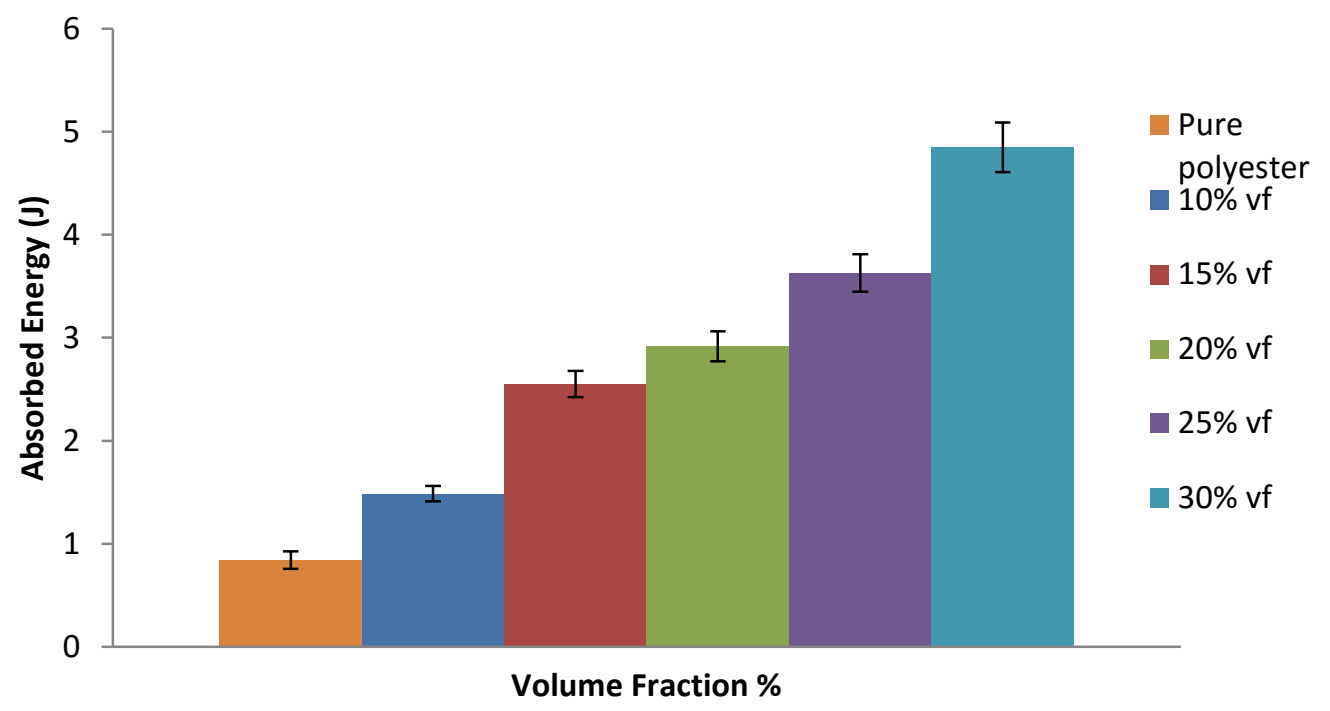

Figure 7. Total energy absorption of Napier grass fibre reinforced composites.

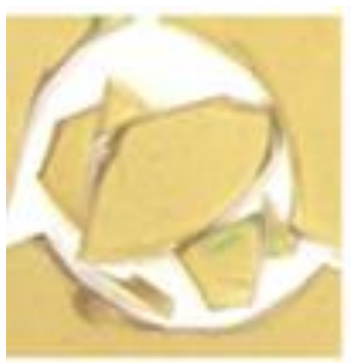

Front face

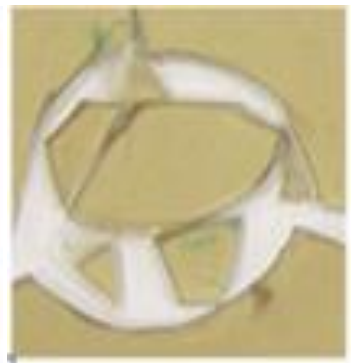

Back face

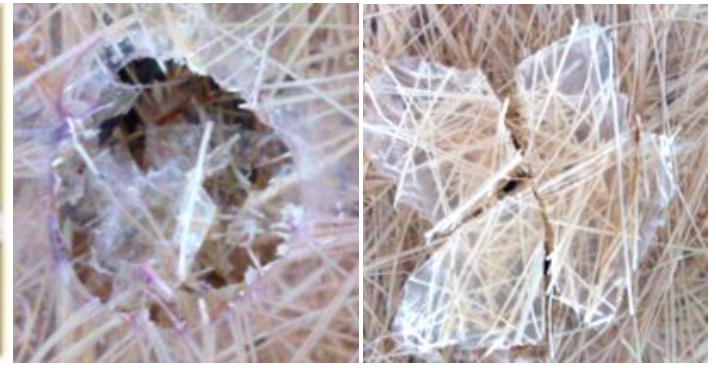

Back face

Figure 8. Impact damage to unreinforced polyester and $10 \%$ volume fraction specimens

\section{Impact damage characteristics}

The fracture patterns in the test specimens after the impact test are shown in Figures 8 to 10. These show that the pure polyester exhibits brittle failure behaviour after the impact test, and the $10 \%$ volume fraction Napier fibre reinforced samples show a $28 \mathrm{~mm}$ diameter hole in the front and the back face, as shown in Figure 8. The fracture features for the $15 \%$ and $20 \%$ volume fraction Napier fibre reinforced samples are illustrated in Figure 9. For the $15 \%$ and $20 \%$ volume fraction specimens, there are about 27 and $25 \mathrm{~mm}$ round damaged areas in the back face and about a $13 \mathrm{~mm}$ round damaged area on the front face. Figure 10 shows that the fractures for the $25 \%$ and $30 \%$ Napier fibre reinforced specimens are approximately 19.9 and $24 \mathrm{~mm}$ round damaged areas in the front face and a $20 \mathrm{~mm}$ radial fracture in the back face. As a proof, a radial fracture is created on the back face of all the Napier fibre reinforced specimens. The Napier reinforced specimens exhibit a long 
propagation condition before final perforation. All the Napier fibre loadings showed extensive matrix cracking and fibre breakage in the centre of their back face, except for the $10 \%$ Napier fibre loading.

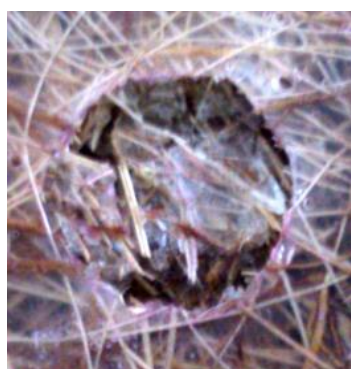

Front face

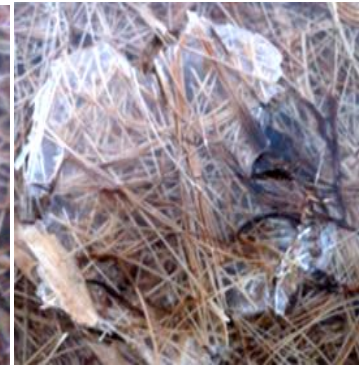

Back face

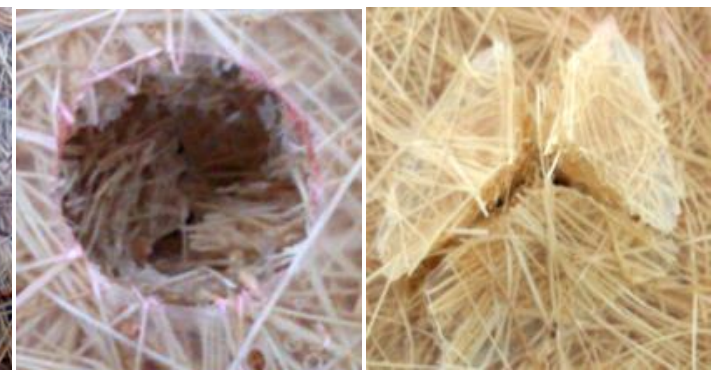

Front face
Back face

Figure 9. Impact damage to $15 \%$ and $20 \%$ volume fraction specimens

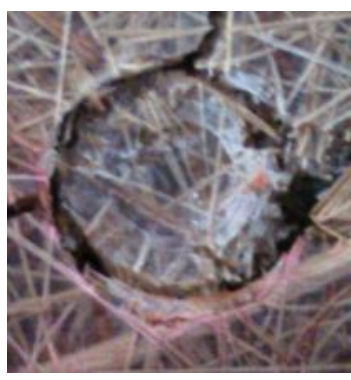

Front face

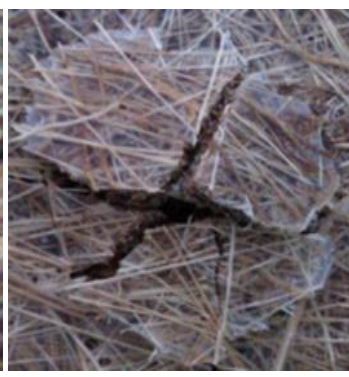

Back face

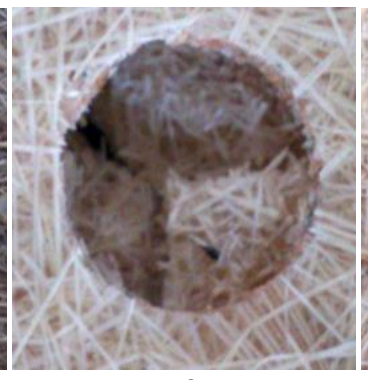

Front face

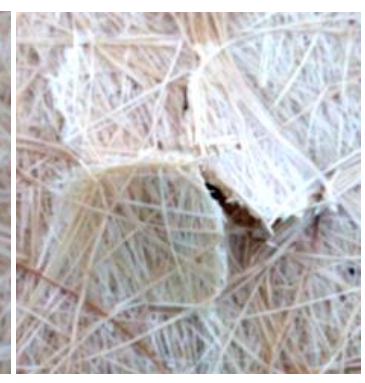

Back face

Figure 10. Impact damage to $25 \%$ and $30 \%$ volume fraction specimens

\section{Failure Mechanism}

Following impact testing, FESEM was utilised to identify the impact damage in the Napier reinforced composites. There are various types of impact damage to composite laminates, such as matrix cracking, delamination, fibre breakage, fibre pull-out and perforation of the impacted surface $[27,28]$. The major step in concentrating on the impact response of composite materials is to portray the sort and augmentation of the damage caused in the impacted samples. Figure 11 shows the FESEM photographs of impacted specimens. The fibre matrix adhesion shows that a combination of matrix cracking, delamination and fibre breakage is the major failure mode that is evident from the impacted specimens. For the $10 \%$ and $15 \%$ fibre volume fraction Napier reinforced specimens, it can be seen that there are empty spaces, with insufficient fibres to control the network and that there are resin-rich zones present. This circumstance can lead to highly localised strain. In the case of the $20 \%, 25 \%$ and $30 \%$ fibre volume fraction Napier reinforced specimens, the matrix wets the fibre and this supports the composite material to show solid interfacial bonding. When there is a strong bond at the interface, impact damage is not engendered in the region of the impacted point and local failure is produced due to localised strain.

A few researchers have reported that as the fibre volume fraction increases, the wettability of fibre with adhesion diminishes, and there may be a lack of interfacial bonding $[29,30]$. The solid interface bonds a fragile crack mode with moderately low energy absorption, though a feeble interface bonds a numerous shear mode with high energy absorption [31]. Usually, this lack of interface bonding is desirable since the 
breaking of weak interfaces can act as an energy absorber and the durability of the composite can increase. Additionally, the impact force can be divided around the encompassing impacted point, which initiates fracture fragmentation and avoids the existing localised strain [32]. However, when the fibre volume fraction grows to beyond its threshold value, the impregnation of resin into the fibre matrix user interface region is reduced and results in a lack of bonding between the matrix and fibre. In this situation, the composite cannot deal with the effects of further loads.
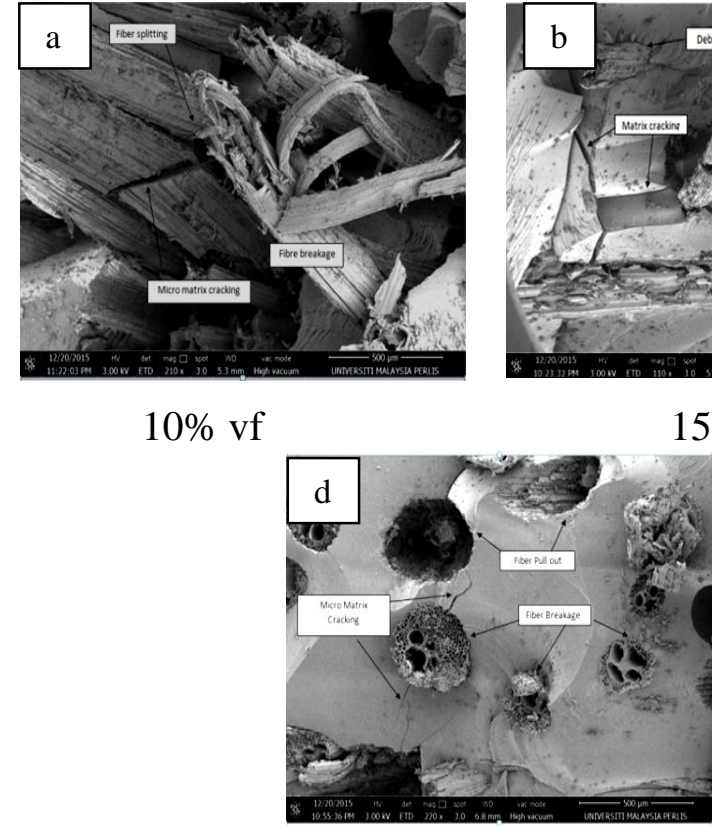

$25 \%$ vf

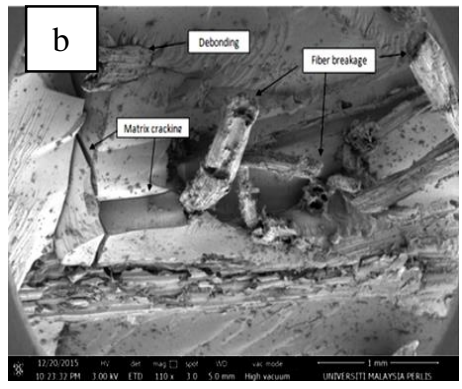

$15 \%$ vf

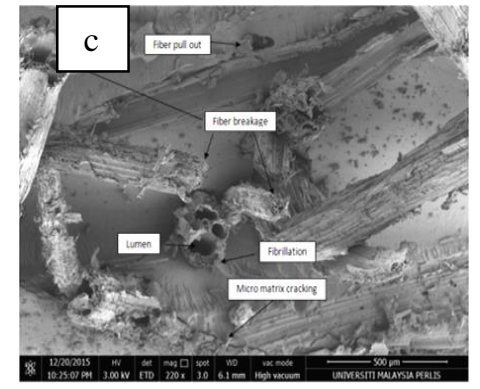

$20 \% \mathrm{vf}$

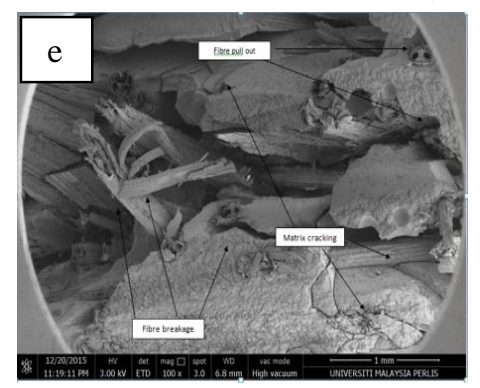

$30 \%$ vf

Figure 11. FESEM of fractured surfaces showing the various failure modes of the composites

\section{CONCLUSIONS}

An experimental low-velocity impact response test was conducted to study the effect of Napier fibre polyester reinforcement of unsaturated polyester. The different fibre volume fractions present increasing peak loads and energy absorption. Addition of $10 \%$ fibre volume fraction increases the peak load and total energy by two times compared with pure polyester. The impact test result showed that the $30 \%$ volume fraction increases the energy absorption by approximately five times more than unsaturated polyester. The time of striker contact with the specimens increased with the increasing fibre volume fraction, which adds to higher peak load and energy absorption. Furthermore, increasing volume fractions also provide impact-resistant properties and increase the damage propagation phase. Impacted specimens with lower fibre volume fractions show brittle fracture type damage compared with higher fibre volume fractions, where the fracture is more ductile due to the higher time of contact and energy absorption. The surface morphology of Napier grass reinforced composite as seen from field emission scanning electron microscopy (FESEM) exposed failure mechanisms such as matrix cracking, delamination, fibre pull-out and fibre breakage, irrespective of the fibre volume fraction. This study suggests Napier reinforcement composite as a good reinforcing material that 
can be employed in engineering applications where the key design factor is energy absorption.

\section{ACKNOWLEDGEMENTS}

The authors would like to thank the Universiti Malaysia Perlis and the Ministry of Education, Malaysia, for providing financial assistance (FRGS No.: 9003-00515). The authors would thank all staff I that involve in this project, especially from the School of Mechatronic Engineering, Universiti Malaysia Perlis (UniMAP), Malaysia.

\section{REFERENCES}

[1] Bolton J. The potential of plant fibres as crops for industrial use. Outlook on Agriculture (United Kingdom). 1995.

[2] Rao KMM, Rao KM, Prasad AR. Fabrication and testing of natural fibre composites: Vakka, sisal, bamboo and banana. Materials \& Design. 2010;31:50813.

[3] Ibrahim MS, Sapuan SM, Faieza AA. Mechanical and thermal properties of composites from unsaturated polyester filled with oil palm ash. Journal of Mechanical Engineering and Sciences. 2012;2:133-47.

[4] Hardinnawirda K, SitiRabiatull Aisha I. Effect of Rice Husks as Filler in Polymer Matrix Composites. Journal of Mechanical Engineering and Sciences. 2012;2:181-6.

[5] Bledzki A, Gassan J. Composites reinforced with cellulose based fibres. Progress in Polymer Science. 1999;24:221-74.

[6] Hepworth DG, Hobson RN, Bruce DM, JW F. The use of untreated hemp fibre in composite manufacture. Composites: Part A 2000;31:1279-83.

[7] Liu Z, Erhan SZ, Akin DE, Barton FE. "Green" composites from renewable resources: preparation of epoxidized soybean oil and flax fiber composites. Journal of Agricultural and Food Chemistry. 2006;54:2134-7.

[8] Roslan SAH, Hassan MZ, Rasid ZA, Zaki SA, Daud Y, Aziz S, et al. Mechanical properties of bamboo reinforced epoxy sandwich structure composites. International Journal of Automotive and Mechanical Engineering. 2015;12:288292.

[9] Fatchurrohman N, Sulaiman S, Sapuan SM, Ariffin MKA, Baharuddin BTHT. Analysis of a metal matrix composites automotive component. International Journal of Automotive and Mechanical Engineering. 2015;11:2531-40.

10] Wan Dalina WAD, Mariatti M, Mohd Ishak ZA, Mohamed AR. Comparison of properties of mwcnt/carbon fibre/ epoxy laminated composites prepared by solvent spraying method. International Journal of Automotive and Mechanical Engineering. 2014;10:1901-9.

[11] Ravi Sankar H, Srikant RR, Vamsi Krishna P, Bhujanga Rao V, Bangaru Babu P. Estimation of the dynamic properties of epoxy glass fabric composites with natural rubber particle inclusions. International Journal of Automotive and Mechanical Engineering. 2013;7:968-80.

[12] Bledzki AK, Gassan J, Zhang W. Impact properties of natural fiber-reinforced epoxy foams. Journal of Cellular Plastics. 1999;35:550-62. 
[13] Wisheart M, Richardson M. Low velocity response of a complex geometry pultruded glass/polyester composite. Journal of Materials Science. 1999;34:110716.

[14] Jeffrey KJT, Tarlochan F, Rahman MM. Residual strength of chop strand mats glass fiber/epoxy composite structures: effect of temperature and water absorption. International Journal of Automotive and Mechanical Engineering. 2011;4:504-19.

[15] Adebisi AA, Maleque MA, Rahman MM. Metal matrix composite brake rotor: historical development and product life cycle analysis. International Journal of Automotive and Mechanical Engineering. 2011;4:471-80.

[16] Wang S, Chung D, Chung JH. Impact damage of carbon fiber polymer-matrix composites, studied by electrical resistance measurement. Composites Part A: Applied Science and Manufacturing. 2005;36:1707-15.

[17] Byun J-H, Song S-W, Lee C-H, Um M-K, Hwang B-S. Impact properties of laminated composites with stitching fibers. Composite Structures. 2006;76:21-7.

[18] Shen W. Dynamic response of rectangular plates under drop mass impact. International Journal of Impact Engineering. 1997;19:207-29.

[19] Cantwell W, Morton J. The impact resistance of composite materials - a review. Composites. 1991;22:347-62.

[20] Bogdanovich A, Friedrich K. Initial and progressive failure analysis of laminated composite structures under dynamic loading. Composite Structures. 1994;27:43956.

[21] Naik N, Sekher YC. Damage in laminated composites due to low velocity impact. Journal of Reinforced Plastics and Composites. 1998;17:1232-63.

[22] Richardson M, Wisheart M. Review of low-velocity impact properties of composite materials. Composites Part A: Applied Science and Manufacturing. 1996;27:1123-31.

[23] Whittingham B, Marshall I, Mitrevski T, Jones R. The response of composite structures with pre-stress subject to low velocity impact damage. Composite Structures. 2004;66:685-98.

[24] Santulli C. Mechanical and Impact Properties of Untreated Jute Fabric Reinforced Polyester Laminates Compared With Different E-Glass Fibre Reinforced Laminates. Science and Engineering of Composite Materials. 2000;9:177-88.

[25] Rout J, Misra M, Tripathy S, Nayak S, Mohanty A. The influence of fibre treatment on the performance of coir-polyester composites. Composites Science and Technology. 2001;61:1303-10.

[26] Sierakowski RL, Chaturvedi SK. Dynamic loading and characterization of fiberreinforced composites; 1997.

[27] Sutherland L, Soares CG. Impact behaviour of typical marine composite laminates. Composites Part B: Engineering. 2006;37:89-100.

[28] Sutherland L, Soares CG. Effects of laminate thickness and reinforcement type on the impact behaviour of E-glass/polyester laminates. Composites Science and Technology.1999;59:2243-60.

[29] Rong MZ, Zhang MQ, Liu Y, Yang GC, Zeng HM. The effect of fiber treatment on the mechanical properties of unidirectional sisal-reinforced epoxy composites. Composites Science and Technology. 2001;61:1437-47.

[30] Mohanty S, Verma SK, Nayak SK. Dynamic mechanical and thermal properties of MAPE treated jute/HDPE composites. Composites Science and Technology. 2006;66:538-47. 
[31] Kim J-K, Mai Y-w. High strength, high fracture toughness fibre composites with interface control—a review. Composites Science and Technology. 1991;41:33378.

[32] Park R, Jang J. A study of the impact properties of composites consisting of surface-modified glass fibers in vinyl ester resin. Composites Science and Technology.1998;58:979-85. 